\title{
Epistemic Invariantism and Speech Act Contextualism
}

\author{
Forthcoming in The Philosophical Review \\ John Turri \\ Huron University College \\ john.turri@gmail.com
}

Abstract: This paper shows how to reconcile epistemic invariantism with the knowledge account of assertion. My basic proposal is that we can comfortably combine invariantism with the knowledge account of assertion by endorsing contextualism about speech acts. My demonstration takes place against the backdrop of recent contextualist attempts to usurp the knowledge account of assertion, most notably Keith DeRose's influential argument that the knowledge account of assertion spells doom for invariantism and enables contextualism's ascendancy. The paper's plan: Section 1 explains contextualism and invariantism. Section 2 recounts a common influential objection to contextualism, to wit, that its proponents confuse warranted assertability with truth. Section 3 reviews DeRose's response to this objection, wherein he argues that contextualism's opponent, in leveling this objection, is hoist with his own petard. Sections 4-6 develop resources for crafting a version of invariantism that escapes DeRose's argument. Section 7 introduces us to this freshly equipped version of invariantism, which can be wedded to the knowledge account of assertion. Sections $8-11$ entertain and respond to objections. Section 12 concludes our discussion by sug- 
gesting how our new invariantist could respond to the radical skeptic, in a way that rivals the anti-skeptical contextualist's response.

\section{Contextualism and Invariantism}

Attributer contextualism in epistemology, hereafter just contextualism, is the view that the truth-conditions of knowledge ascriptions, such as 'S knows that P', are context-sensitive. In particular, knowledge ascriptions are context-sensitive in virtue of 'knows' being context-sensitive. ${ }^{1}$ The attributer's context determines how strong an epistemic position $\mathrm{S}$ must be in with respect to $\mathrm{P}$ in order for ' $\mathrm{S}$ knows that $\mathrm{P}$ ' to express a truth in the attributer's mouth. Thus an attributer in one context could truly say 'S knows that P', while simultaneously an attributer in a different context could refer to the same person at the same time with respect to the same proposition, and truly say ' $\mathrm{S}$ does not know that $\mathrm{P}$ '. Invariantism denies that the truth-conditions of knowledge ascriptions are context-sensitive. They remain constant, invariantists say, across contexts.

Why think contextualism is true? First, it provides a principled and subtle response to the skeptic, vindicating commonsense intuitions that we know many things, while also giving the skeptic her

Cohen $(1988,97)$, for example, says 'knows' is an indexical-in the Kaplanian sense of having an invariant character that is a function from contexts to content-which predicates different properties in different contexts, just as 'I' denotes different individuals in different contexts. See also Schaffer 2004. All of this, of course, pertains only to 'knows' as it appears in propositional knowledge ascriptions. 
due by explaining skepticism's appeal and the extent to which it gets things right (DeRose 1995, Cohen 2005). Some think this concedes too much to skepticism. They think that we should explain skepticism's initial plausibility only, but this need not-indeed, ought not-involve conceding that skepticism is at all true (Sosa 1999, 147; Conee 2005, $54-5$ ). I do not aim to resolve this dispute here, although the paper's final section presents a positive proposal that would complement this criticism of contextualism.

Second, there are imaginary yet entirely realistic conversations wherein the protagonist says ' $\mathrm{I}$ know that $\mathrm{P}$ ' in an ordinary "lowstakes" setting, and it seems that he says something true; yet we can pair this with a "high-stakes" setting wherein something important rests on whether $P$, the participants take seriously ways in which $P$ might turn out to be false despite the evidence at hand, and the protagonist not only demurs on the question whether he knows that $\mathrm{P}$, but we also intuit that it would be false were he to say 'I know that P'. DeRose's $(1992,913)$ pair of bank cases is probably the most famous example of this phenomenon. (See also Cohen's $(1999,58)$ airport cases.) Contextualists claim that such pairs provide excellent support for their view. For the apparent truth of knowledge ascriptions varies in response to a change in context. The stakes rise, alternative possibilities are seriously considered, and the intuition that it would be incorrect for the protagonist to self-ascribe knowledge becomes strong. That, contextualists will say, is because we are implicitly sensitive to the way context affects the truth-conditions of knowledge ascriptions. 


\section{The Generality Objection}

We encounter a popular objection to this last line of reasoning offered in support of contextualism, what DeRose (2002) calls a "warranted assertability maneuver" or "WAM" for short. A WAMmer objects that the contextualist confuses warranted assertability with truth. It is appropriate in the low-stakes setting for our protagonist to assert that he knows $\mathrm{P}$, but inappropriate in the highstakes setting for him to assert the same. In the high-stakes case it might even be appropriate for him to falsely assert that he does not know $\mathrm{P}$, because this might be the only way to avoid generating false or misleading implications that could have significant negative consequences if acted upon.

DeRose thinks there is something to this, but we must carefully formulate the insight to properly assess its significance. Indiscriminate WAMming will lead to some ugly results, for we could use the strategy to defend even the most implausible of theories. As DeRose puts it, "Whenever your theory seems to be wrong because it is omitting a certain truth-condition ... you can simply claim that assertions of the sentences in question generate implicatures to the effect that the condition in question holds" (DeRose 2002, 173). Consider this view: $\mathrm{S}$ knows that $\mathrm{P}$ just in case $\mathrm{S}$ believes that $\mathrm{P}$. Of course it seems false to say 'S knows that P' when $\mathrm{S}$ has a false unjustified belief that $\mathrm{P}$, but that is only because saying ' $\mathrm{S}$ knows that P' generates the (in this case) false implicature that $\mathrm{S}^{\prime}$ s belief is true 
and justified! ${ }^{2}$

WAMming will persuade only when it invokes general rather than special one-off conversational rules that generate the relevant implicatures. Does the WAM criticism of contextualism display this feature?

DeRose thinks it can (although ultimately the necessary refinements play right into the contextualist's hands-more on that shortly). Here is the basic idea. It is a general conversational rule that you ought to assert something only if you are well enough positioned epistemically to assert it in the context. Not only does the (warranted) assertability of 'I know that P' shift with context, so does that of the unadorned ' $\mathrm{P}$ '. Yet on most substitutions for ' $\mathrm{P}$ ' (for example, 'the bank is open Saturdays' or 'the door is locked') we are not tempted to think that its truth-conditions shift with context. But this bodes ill for contextualism. We can no longer motivate contextualism by a need to explain what changes from the low- to highstakes case, because we can explain that just by noting that the assertability conditions for ' $\mathrm{P}$ ' change, and ' $\mathrm{I}$ know that P' straightforwardly entails ' $\mathrm{P}$ ', so obviously the assertability conditions for the latter will change as well. ${ }^{3}$ We need not posit shifting truth-conditions for knowledge ascriptions when an explanation predicated on general conversational rules suffices. DeRose calls this the Generality Objection and he honestly acknowledges its force.

2 See the entertaining tale of Jank Fraction in DeRose 2002, section 1.3.

3 See Hazlett forthcoming for an argument that 'I know that $P$ ' does not entail ' $P$ '. 


\section{A "Lethal" Response}

But DeRose also has an ingenious response, which we might encapsulate as follows. First recall that the Generality Objection itself is predicated on the observation that assertability is context-sensitive. Next let's give some content to the vague formulation of the conversational rule, essential to the Generality Objection, enjoining us to assert that $\mathrm{P}$ only if we are "well enough positioned" relative to $\mathrm{P}$. What is well enough positioned? Answer: knowing. DeRose identifies the relevant norm as: "one is positioned well enough to assert that P iff one knows that P" (DeRose 2002, 180). ${ }^{4}$ Call this the knowledge account of assertion. I shall grant this for the sake of argument. But notice now how close the invariantist has come to sealing his own fate.

From here it is virtually no leap at all to the conclusion that the truth-conditions for knowledge ascriptions shift with context. Put simply, given that

(1) $S$ knows that $P$ iff $S$ is well enough positioned to assert that $P$, and

(2) whether $\mathrm{S}$ is well enough positioned to assert that $\mathrm{P}$ shifts with context,

it follows that,

(3) the truth-conditions for 'S knows that P' shift with context.

4 See also Williamson 2000, chapter 11, and Hawthorne 2004, chapter 1.3. Not all theorists sympathetic to DeRose agree that knowledge is necessary and sufficient to be well enough positioned. 
And 3 just is the contextualist thesis. Earlier I said that the inference involves "virtually" no leap because one might suspect it involves some illicit disquotation. ${ }^{5}$ But I will ignore any such suggestion and grant that the argument is valid, or in any case initially quite compelling.

DeRose concludes, "Given how secure is the premise that assertability is context-variable, the knowledge account of assertion, which provides the only other premise needed to establish contextualism, is lethal to invariantism" (DeRose 2002, 188). ${ }^{6}$

But is it indeed lethal? I think not. Invariantists have the resources to explain all the data and retain the knowledge account of assertion without conceding that assertability is context-sensitive, that is, without accepting premise 2 of DeRose's argument. ${ }^{7}$ In or-

5 Thomas Blackson (2004) argues that it is invalid for a different reason; see note 7 for more detail.

6 My exposition in this section inevitably overlooks some subtleties of DeRose's detailed critical treatment of the Generality Objection and his positive argument for contextualism via the knowledge account of assertion. Nevertheless, I believe it neatly and succinctly captures the basic idea in way that promotes the present paper's main goal.

7 My response thus differs fundamentally from Blackson's (2004) response. Blackson responds that DeRose's argument (what I represent above as $1-3$ ) is invalid because it ignores possible versions of invariantism, especially what is known in the literature variously as "sensitive moderate invariantism" (Hawthorne 2004, chapter 4), "interest-relative invariantism" (Stanley 2005, chapter 5), and "subject sensitive invariantism" (DeRose 2004). (See also Fantl and McGrath 2002 and 2007.) By contrast I respond by challenging the truth of one of DeRose's premises. It's worth having both responses at our disposal.

Whereas contextualists say that features of the attributor's context affect the truth-conditions of knowledge ascriptions, subject sensitive invariantists say that knowledge itself is essentially affected 
der to demonstrate this, I must first set in place some concepts and distinctions. The next three sections accomplish this.

\section{Speech Acts and Company}

When you string together words in a way that satisfies the semantic and grammatical conventions of a particular language, you say something meaningful in that language. The act of saying something meaningful in a language is a linguistic act.

In performing a linguistic act, we often do further things. In uttering 'I promise to come to your party' I promise to come to your party. In uttering 'It starts at eight' you assert that it starts at eight. In uttering 'I apologize for forgetting about your party' I apologize for forgetting about your party. A speech act is that which you do in performing a linguistic act. Promising, asserting, and apologizing are all speech acts.

The same linguistic act could be used to perform different

by the subject's practical situation, and attempt to explain all the relevant data on that basis. It is controversial that purely practical matters, such as how much is at stake for the subject, are essentially connected with how much the subject knows. Subject sensitive invariantism also faces problems with mixed knowledge-attributions involving subjects in very different practical situations, as DeRose (2004) and Schaffer (2006) argue, and as Hawthorne (2004, 180 n.44) himself recognizes.

The view I suggest in this paper is consistent with, but does not presuppose, subject sensitive invariantism. It remains to be confronted even by those contextualists who, like DeRose and Schaffer, reject subject sensitive invariantism. 
speech acts, depending on the context. Consider: ${ }^{8}$

I.
A: Have you been to Boston before?
B: Yes.

II.
A: Do you promise that you'll come to my party?

B: Yes.

III.

A: Do you swear to abide by the laws of Canada?

B: Yes.

IV.

A: Do you apologize for your rude behavior?

B: Yes.

V.
A: Do you recant your testimony?
B: Yes.

In performing the linguistic act of uttering 'yes' in cases I - V, B variously asserts, promises, swears, apologizes, and recants. Consider also: ${ }^{9}$

VI.

A: Come on, make a prediction.

B: You will not speak in class today.

VII.

A: What is your order?

B: You will not speak in class today.

In performing the linguistic act of uttering 'You will not speak in

8 Compare Fogelin and Sinnott-Armstrong 1997, 10.

9 Compare Unger 1975, 266. 
class today', B makes a prediction in case VI but issues an order in VII. (This would be true even if the two token utterances were $e x-$ actly similar in terms of enunciation, tone, inflection, tempo, etc.) In all of these cases, the context of utterance helps determine which speech act is performed.

Assertion is the default value of a declarative utterance in English and, I presume, other natural languages as well (Williamson 2000, 258). Its default status means that normally declarations count as assertions and no more-that is, normally in uttering the declarative sentence 'Q', you assert that $Q$. But context can affect this. For instance in a court of law you may be asked to take an oath of testimony. You may be asked to swear to the truth of what you are about to say. Having sworn to the truth of your impending testimony, in uttering 'Q' you are swearing that Q. Should you utter 'The defendant entered the building before dusk', you thereby swear that the defendant entered the building before dusk..$^{10}$

Let speech act contextualism be the view that context affects which speech act you perform in performing a linguistic act. ${ }^{11}$

${ }^{10}$ Consistent with this, you might still assert too. It might even be that you swear by asserting.

"Speech act contextualism differs from Cappelen and Lepore's (2005) "Speech Act Pluralism." Speech act pluralism is a view about what is asserted by an utterance. They summarize their view like so: "No one thing is said (or asserted, or claimed, or . . .) by any utterance: rather, indefinitely many propositions are said, asserted, claimed, stated. What is said (asserted, claimed, etc.) depends on a wide range of facts other than the proposition semantically expressed. It depends on a potentially indefinite number of features of the context of utterance and of the context of those who report on (or think about) what was said by the utterance." Cappelen and 
We perform speech acts in order to accomplish things. We rarely perform a speech act for its own sake. I assert that this bottle of water contains a lethal amount of arsenic in order to make you aware that it contains a lethal amount of arsenic; if all goes well, I make you aware by telling you. I beg you not to drink the liquid in order to persuade you not to; if all goes well, I persuade you by begging you. A conversational act is the act of affecting your conversational partner by performing a speech act in a conversation. In the first example above, the speech act is assertion and the conversational act is making aware or alerting. In the second example, the speech act is begging and the conversational act is persuasion.

We perform a conversational act by performing a speech act, but the two are distinct. Consider what would happen if you weren't paying attention to me when I asserted that the bottle contains a lethal amount of arsenic: I would still have made the assertion, but I would not have made you aware of the relevant fact. My making you aware requires your cooperation, which may or may not be forthcoming. ${ }^{12}$

Lepore 2005, 4; see also $199 \mathrm{ff}$.

${ }^{12}$ The general picture of language sketched in this section derives ultimately from Austin 1962, through the lens of Fogelin and SinnottArmstrong 1997, chapter 1. Following Fogelin and Sinnott-Armstrong, what Austin calls a "locutionary act" I call a "linguistic act," what Austin calls an "illocutionary act" I call a "speech act," and what Austin calls a "perlocutionary act" I call a "conversational act." See Austin 1962, esp. $102-3,108$. 


\section{Truth, Credibility and Requirements}

Other things equal, insofar as an assertion is true, it is good qua assertion; insofar as an assertion is false, it is bad qua assertion. ${ }^{13}$ Of course the consequences of asserting the truth on some occasion may be bad, so it might be bad all things considered to assert that particular truth at that particular time. Likewise the consequences of asserting the false on some occasion may be good, so it might be good all things considered to assert that particular falsehood at that particular time. But this should not obscure the original point that, other things equal, asserting the true is good and asserting the false bad. For convenience we might summarize this by saying truth governs assertion or assertion aims at truth. I adopt the latter.

Other speech acts aim at truth. Consider conjecture. Other things equal, insofar as a conjecture is true, it is good qua conjecture; insofar as it is false, it is bad qua conjecture. The same qualifications that held for assertion also hold for conjecture: a false conjecture might be good all things considered, and a true conjecture bad all things considered. Analogous points apply to the speech acts of guessing, guaranteeing, and swearing. Let's call this family of speech acts that aim at truth alethic speech acts.

We can make finer distinctions if we like. Let ' $\Phi$ ' range over

${ }^{13}$ Williamson $(2000,244 \mathrm{ff})$ makes many of the points enumerated in this section, though for a different purpose. Williamson aims to discredit the truth account of assertion, according to which 'One must: assert $p$ only if $p$ is true' is the constitutive rule of assertion. Williamson favors the knowledge account, according to which 'One must: assert $p$ only if one knows $p$ ' is the constitutive rule of assertion. 
alethic speech acts. For at least many $\Phi$, and at least some adverbs, we can also adverbially- $\Phi$. For example, you can swear and then you can solemnly swear; you can assert and then you can confidently or qualifiedly assert. For present purposes we needn't decide whether to count adverbially-Фing as a distinct speech act from Фing.

Asserting that Q places more of your credibility on the line than conjecturing that $\mathrm{Q}$. Swearing that $\mathrm{Q}$ places more of your credibility on the line than merely asserting that Q. Let's call the amount of credibility you place on the line by making an alethic speech act its credibility requirement. Even if adverbially-Фing doesn't count as a distinct speech act from $\Phi$ ing, adverbial qualification affects the amount of credibility required. Confidently conjecturing extracts more credibility than just plain conjecturing. Confidently asserting extracts more credibility than just plain asserting, and the latter more than making a hedged assertion. Solemnly swearing extracts more credibility than just plain swearing. Absolutely guaranteeing extracts more credibility than just plain guaranteeing.

Competent speakers can intuitively sort credibility requirements along a spectrum. Call the resulting ordering the credibility index for alethic speech acts. The lesser a speech act's credibility requirement, the lower it ranks on the index; the greater the requirement, the higher it ranks. Guessing ranks lower than conjecturing, conjecturing lower than assertion, and assertion lower than swearing. Someone who sincerely believed that conjecturing ranked higher than asserting would thereby demonstrate some measure of lin- 
guistic incompetence. But linguistic conventions are not rigorous or explicit enough to produce a perfectly well-ordered index, or to compel complete agreement among even fully competent speakers. For example, it is not entirely clear whether swearing or guaranteeing ranks higher. If I judge swearing to rank higher, others may sincerely disagree without thereby demonstrating linguistic incompetence. Neither does the index precisely rank adverbial modification of one speech act relative to another. Conjecture ranks lower than assertion, but does confidently conjecturing rank lower than qualifiedly asserting? It is not clear. Present purposes permit us to leave the matter unsettled.

The higher an alethic speech act ranks on the credibility index, the stricter the epistemic norms that govern it. In other words, the greater the credibility requirement, the greater the corresponding epistemic requirement. Corresponding to the credibility index, then, is an epistemic index for alethic speech acts. Guessing has the most relaxed epistemic requirement of all these. Let a pure blind guess be a guess where your total evidence is indifferent among any and all relevant options. Pure blind guessing extracts no credibility and so carries no epistemic requirement. You are required, at most, only to not guess against your evidence. ${ }^{14}$ Conjecturing has stricter epistemic requirements than guessing. Asserting has stricter epistemic requirements than conjecturing. Swearing and guaranteeing

\footnotetext{
${ }^{14}$ Suppose you're asked to guess whether $Q$ or $R$. If your evidence on balance indicates that one of the options is more likely, then you ought to guess that option, and if you guess otherwise, then the resulting guess would to that extent be bad.
} 
have stricter epistemic requirements than asserting.

A metaphor may help bring this all together. Think of language use as a game we continually play in order to achieve our individual and collective goals; think of a conversation as a round in the game; and think of the various alethic speech acts as possible moves in the game. You can play a round with anyone who's willing to play with you. Each person starts the game with a certain amount of currency called "credibility," held in an account with a rolling balance. Making a move requires a deposit, known as the move's "credibility requirement," the amount of which is listed in the "credibility index" of the game's instruction manual. Guessing is free; conjecturing is cheap; asserting is neither cheap nor expensive; guaranteeing and swearing are expensive. When you move, the house extracts a deposit from your credibility account and holds it in escrow. Once your move is complete, the house refunds your deposit only if (or, perhaps, to the extent that) you met certain predefined standards, known as the move's "epistemic requirement," detailed in the manual's "epistemic index." If you did not meet the epistemic requirements when you made your move, you lose your deposit; if you did, you recover your deposit, often times with interest.

\section{Relative Ranking}

The relative ranking of alethic speech acts in the credibility and epistemic indices is clear enough. We should not expect precision in specifying absolute epistemic requirements. Short of technical stip- 
ulation-and even with a moderate dose of that-a plausible approximate qualitative specification is the most we can reasonably hope for.

To aid our discussion, I shall adopt and leave undefined the intuitive idiom of probability on your evidence, and I shall assume that knowledge requires a probability of 1 on your evidence. Let me emphasize that nothing in my discussion essentially depends upon either the aid or the assumption: I employ them purely for convenience. The knowledge account of assertion will provide a helpful benchmark to guide our discussion.

The epistemic requirement for assertion is knowledge. The requirement for guessing or conjecturing is something less than knowledge. The requirement for swearing or guaranteeing is something greater than knowledge. ${ }^{15}$ Assuming that knowledge requires a probability of 1 on your evidence, you are well-enough positioned to assert that $\mathrm{Q}$ if and only if $\mathrm{Q}$ has a probability of 1 on your evidence.

If knowledge requires a probability of 1 on your evidence, what more is required for guaranteeing? It cannot be a probability great-

${ }^{15}$ A referee finds it implausible that there are "augmented epistemic states above knowing." I find that things seem otherwise to me, for at least three reasons. First, one person can know something better than another, so there exist grades of knowledge beyond the bare minimum required to know. Second, knowing that you know constitutes a greater epistemic achievement than merely knowing. Third, understanding why $Q$ requires not only knowing that $Q$, but also knowing what explains Q. Knowing full well, knowledge of knowledge, and understanding are all plausible candidates for "augmented epistemic states" above mere knowledge. 
er than 1 , because 1 is by definition probability's upper limit. A range of alternatives suggests itself. Perhaps it is knowing full well that $\mathrm{Q}$, where this requires the probability of $\mathrm{Q}$ on your evidence to be overdetermined at 1 . This in turn requires you to have a surfeit of evidence for Q, such that were you to lose some of it, and gain no further evidence favoring it, the probability of $Q$ on your evidence would still be 1 . Or perhaps it must be more probable than not on your evidence that you know that Q, or highly probable on your evidence that you know that Q. Or, finally, consider this intuitive suggestion. ${ }^{16}$ The epistemic requirement on guaranteeing is knowledge of knowledge: you are well-enough positioned to guarantee that Q only if you know that you know that Q. Call this the KK account of guaranteeing. ${ }^{17}$ Any of these suggestions will suffice for

${ }^{16}$ Compare Austin 1946, 99 - 100.

17 The KK account of guaranteeing would provide another reason to prize what Ernest Sosa calls "reflective knowledge." Sosa $(2007,32)$ defines reflectively knowing that $Q$ as having animal knowledge that you know that $Q$ : "If $K$ represents animal knowledge and $K+$ reflective knowledge, then the basic idea may be represented thus: $\mathrm{K}+\mathrm{q} \leftrightarrow \mathrm{KKq}$." Reflective knowledge figures centrally in Sosa's important and influential epistemology. Yet elsewhere Sosa $(2004,291)$ finds himself forced to grapple with the question: what is so important about this sort of knowledge? We could define another category of knowledge, reflected knowledge, thus: you have reflected knowledge that $Q$ if and only if you know that $Q$ and someone else knows that you know that $Q$. (Sosa considers the alternative category of "consultative knowledge," but reflected knowledge does just as well.) So we ask, "Why the pride of place for reflective knowledge?"

Sosa is keenly aware of how deeply knowledge is intertwined with the social (see, for example, Sosa 1991, 26, 48 - 49, 275 - 276). And so, while recognizing the probative force of his response to the question just posed, we may offer in a friendly spirit this additional 
present purposes, though I prefer the KK account.

\section{The Invariantist Alternative}

We now have the tools to introduce our freshly equipped version of invariantism, which can be wedded to the knowledge account of assertion to defuse DeRose's argument. Here is my pair of toy cases:

The Door Case, low-stakes version (Low Door): Our family is taking a short walk to the corner to place a letter in the mailbox, which is within plain sight of our front door. We have a policy of locking our door when we leave the premises, and we prefer to follow through on our policies. As we reach the end of the driveway on our way to the mailbox, my wife asks, "Is the door locked?" I respond, "Yes, it's locked. I remember turning the key and feeling it click." "Maybe you're mistaken; you do sometimes make mistakes," she remarks. "It's locked," I reply. "All right," she says.

The Door Case, high-stakes version (High Door): Our family has just pulled out of the driveway, on the beginning of a week-long vacation to New Hampshire's White Mountains. We live in a relatively safe neighborhood, but there has been a rash of burglaries lately. As we near the corner of our block, my wife asks, "Is the door locked?” I respond, "Yes, it's locked. I remember turning the key

suggestion. Reflective knowledge is important because it enables us to engage in the important social practice of guaranteeing. (A promise is plausibly regarded as a special type of guarantee, perhaps distinguished by being properly offered only when the promisor and promisee are somehow intimate.) Reflective knowledge is the norm of guaranteeing. Reflected knowledge is not. 
and feeling it click." My wife reminds me of the recent string of burglaries and points out how devastating it would be were we to return from our trip only to find our home ransacked and our belongings stolen. She continues, "It's rare, but sometimes the bolt hits the strike plate in such a way that it clicks but doesn't lock. So ... I ask again: Is it locked?" "I think it's locked, but I'd better go back and check," I reply. “All right,” she says.

Why am I willing to repeat 'It's locked' upon questioning in Low Door but not High Door? The contextualist explanation, supplemented by the knowledge account of assertion, goes like this. In Low Door, I know throughout that the door is locked, so it is okay to reassert that the door is locked. In High Door, I do not know that the door is locked after my wife's speech, so it is not okay to reassert that the door is locked. The hedged claim, not the bald one, is appropriate, and I am tacitly sensitive to this, which explains my linguistic behavior.

The contextualist explanation assumes that throughout both cases uttering 'It's locked' amounts to merely asserting that the door is locked. DeRose, for example, thinks that this is obvious. As he puts it, in uttering ' $\mathrm{P}$ ', " $\mathrm{S}$ (of course) asserts that $\mathrm{P}$ " (DeRose 2002, 185). But it is not obvious. ${ }^{18}$ Assertion may be the default value of a declarative utterance, but context can alter this, as we

${ }^{18}$ Some don't always clearly distinguish uttering ' $P$ ' from asserting that P. But they're not the same thing. We make assertions by uttering sentences. I recognize that it may ordinarily be acceptable to say that one "asserted" a sentence. Nevertheless, I believe this to be misuse of words, though one I would be reluctant to remark upon, save for special circumstances. 
have already seen.

The invariantist can explain matters as follows. Throughout Low Door, uttering 'It's locked' amounts to no more than asserting that it is locked. I am in a position to assert that it is locked both before and after my wife's speech, so uttering 'It's locked' and thereby asserting that it's locked is appropriate both times. In High Door, before my wife's speech, my uttering 'It's locked' amounts to no more than asserting that it is locked, and I am in a position to do that because I know that it is locked. But my wife's speech raises the stakes and we shift context. Now uttering 'It's locked' is to perform an alethic speech act higher up the credibility and epistemic indices. For convenience let's say it is guaranteeing. ${ }^{19} \mathrm{I}$ am tacitly aware of this shift, as well as the fact that I am not in a strong enough position to guarantee that the door is locked, so I do not respond with 'It's locked' but rather 'I think it's locked'. I then embark on the task of gathering enough extra evidence-double- or maybe even triplechecking-to position myself to come back and offer her the guarantee by saying 'Yep, it's locked'.

Recall what explicitly occurs when you take an oath of testimony in a court of law. You swear to tell the truth. Now when you sincerely utter ' $Q$ ' you are not merely asserting that $Q$, but swearing that $\mathrm{Q}$. On the view I am suggesting, something like this happens in

19 Anticipating an understandable objection considered in more detail below, let me emphasize that it does not matter whether we call it "guaranteeing." What matters is that, whatever speech act repeating 'It's locked' would amount to, it would extract more credibility than mere assertion. 
High Door when my wife makes it painfully obvious how much is at stake and explicitly challenges me to stand by my words. Moreover, I am tacitly sensitive to this shift. Surely the contextualist cannot plausibly object to this latter aspect of my proposal, as it would be exceedingly odd to insist that we could detect a shift when it affects truth-conditions, but not when it affects speech acts.

In a word, on my view what shifts is which speech act one performs in uttering a declarative sentence. This is an instance of the more general phenomenon of speech act contextualism. The standards for appropriate assertion and knowledge remain invariant.

Thus the invariantist can accept the knowledge account of assertion and explain the linguistic data without accepting that assertability is context-sensitive. Speech act contextualism is the key. And by embracing it the invariantist denies DeRose a pathway to contextualism through assertion. ${ }^{20}$

${ }^{20}$ A referee asks whether the contextualist and I agree on what the data are. I believe that we can agree on all the uncontroversial data, which consist primarily of our estimation of overt linguistic behavior in the relevant real and imaginary cases. Is their speech correct or incorrect? Of course, the contextualist and I will often disagree over what the correctness or incorrectness consists in. (For example, whereas I might say they made an unwarranted guarantee, the contextualist would say they made an unwarranted assertion.) But that's a theoretical dispute over how to explain the data, not over what the data are. In the present context, I could not properly treat as a datum the claim that epistemic standards are invariant across contexts. Likewise, the contextualist could not properly treat as a datum the claim that epistemic standards "vary with context even in ordinary, nonphilosophical conversations" (DeRose 1999, 195; see also DeRose 2002, 169). (Note: DeRose does not treat it as a datum in the passage quoted; he deploys it as part of his theory, especially his treatment of skepticism.) 


\section{Why It Counts as Guaranteeing}

Doubtless context can affect which speech act you perform with a declarative utterance. But why think that it occurs in the way my account requires?

We perform speech acts for a purpose. In both versions of the Door Case, my goal was to assure my wife that the door was locked. I sought to assure her by asserting that it was locked. But in High Door her speech made it clear that, given what was at stake, mere assertion wouldn't suffice to assure her; I would have to put more credibility on the line to accomplish that. This was mutually understood. She also made it clear that she wanted to be assured, otherwise she wouldn't be asking the question again. This was also mutually understood. In repeating the question, she challenged me to stand by my words, implying that doing so would suffice to assure her. But since assuring her would require more than mere assertion, standing by my words must then count as more than mere assertion. It would count as guaranteeing.

\section{Scorekeeping}

My theory requires that there be something like a "pragmatic force of a declarative utterance" component on the conversational scorecard. Is there any empirical evidence for thinking that things work this way? ${ }^{21}$

${ }^{21}$ Thanks to Jonathan Schaffer for raising this question. 
Yes. Consider this perfectly realistic example. A witness takes the oath of testimony. The prosecutor asks her a question: Did the defendant enter the building before dusk? There follows a series of questions for clarification and consequent clarifications: Q: Dusk on which date? A: October 7, 2007. Q: Which building? A: The opera house in Sydney. Etc. Many turns later, the witness utters 'Yes, the defendant entered the building before dusk'. Everyone understands this to be sworn testimony that the defendant entered the building before dusk. This common understanding is best explained by the hypothesis that swearing is recorded on the scorecard as the force of the witness's declarative utterances.

The facts actually require a more subtle explanation than that. The scorecard records swearing as the force of the witness's declarative utterances, when offered in response to questioning by an officer of the court, when such pertains to material facts of the case at hand. Assertion would still be the force of many other potential declarative utterances by the witness. For instance, if she uttered 'I cannot hear you' or 'excuse me, I need to use the washroom', no one would understand her to be swearing that she could not hear the prosecutor, or that she needed to use the washroom. Nor would she count as swearing to those things. Likewise if a heckler stood up and shouted 'Hey, weren't you on Jeopardy! last week?' and our witness replied 'No, I was not', no one would understand her as swearing that she hadn't been on Jeopardy! last week. That people easily navigate these subtleties suggests that the scorecard carefully tracks the pragmatic force of declarative utterances. 
Consider another example. Elaine is planning a party. She announces it over lunch with several of her friends and says 'Now don't say you'll come unless you absolutely promise to come'. In response, Sally utters 'I'll come to your party, Elaine'. This is understood by everyone as a promise to come. This common understanding is best explained by the hypothesis that promising has been recorded on the scorecard as the force of a declarative utterance such as 'I'll come to your party, Elaine'. Had Sally added 'And I'll bring guacamole', it would not have likewise counted as promising to bring guacamole.

\section{Conventional Mechanisms}

What's the mechanism by which we achieve a shift in context?

Convention determines the mechanisms. Imagine a community of mute persons who communicate by writing with chalk on small blackboards that they carry around with them. ${ }^{22}$ They have different color chalk for different purposes. If one of them, Jones, writes a declarative sentence ' $Q$ ' in yellow chalk on his board and presents it to his interlocutor, Smith, then by convention this counts as Jones asserting that Q. If Smith chooses, she may hand Jones a piece of purple chalk and gesture towards his board. If Jones accepts the chalk and uses it to re-trace 'Q' on his board, then by convention this counts as Jones guaranteeing that Q. Community members typically "pass the purple chalk" only if something important is at stake

22 Just as Louis does in E. B. White's classic The Trumpet of the Swan. 
and they need special assurance that a bit of information is reliable. ${ }^{23}$

In our community a speech like my wife's in High Door is the equivalent of passing the purple chalk. Explicitly challenging someone to stand by his words seems to be a common way of relevantly affecting the conversational context, an effect often (though not always) amplified by emphasizing urgent practical matters. In another community it might be eccentrically tying your shoelaces in triple knots. In another it might be to slap your interlocutor across the lips. The possibilities are limitless.

\section{Call It What You Want}

What if the contextualist responds by arguing that, on the one hand, to guarantee is just to emphatically assert, and on the other, that to adverbially- $\Phi$ is not a different speech act from $\Phi$ ing? If correct, wouldn't this ruin my argument?

No. Instead of a qualitative model featuring a spectrum of different types of speech act, we then get a qualitative model featuring a spectrum of different grades of a single speech act. The latter approach would say that context affects how emphatically you assert by making a declarative utterance. Emphatically asserting extracts more credibility than simply asserting, just as simply asserting ex-

23 James Dreier suggested to me that this sort of example-where writing something in purple chalk amounts to guaranteeing or promising or some such thing-might be originally due to Elizabeth Anscombe. I cannot find a reference. 
tracts more credibility than qualifiedly asserting. Consequently, emphatic assertion's epistemic requirement will be greater than (simple) assertion's, which requirement is knowledge. In High Door, I don't repeat 'It's locked' because I tacitly recognize that doing so would constitute an emphatic assertion, and that I don't meet the epistemic requirements for emphatic assertion. Etc. We can call guaranteeing 'emphatically asserting' if we like, but that will not change the basic underlying intuitive facts that inspire the invariantist alternative. ${ }^{24}$

${ }^{24}$ A referee suggests that the scale of speech acts might not be as fine-grained as the scale of epistemic standards, which in turn might disadvantage my view. Standards can vary to any degree we like, but the same is not true for speech acts, even when we allow for adverbial modification (for example, asserting vs. qualifiedly asserting; swearing vs. solemnly swearing; etc.) This arguably favors contextualists because their view will have resources to respect "the endlessly variegated demands of context" where mine might falter.

It seems to me that my view can well match contextualism's versatility here, for two reasons. First, adverbial modification enables significant versatility, so much so that any advantage contextualism scores here will be slight indeed.

Second, if the contextualist's epistemic standards can vary continuously along a scale, then so can the amount of credibility extracted by a declaration vary endlessly in response to context. Crude versions of epistemic contextualism posit two senses of 'know', or two epistemic standards, low and high. But as DeRose $(1999,192-5)$ has explained, the most plausible versions of contextualism posit "a wide variety of different standards." Likewise, crude versions of speech act contextualism might hew closely to the qualitative and discontinuous scale of alethic speech acts named in ordinary language. But more sophisticated versions might view that scale as merely a serviceable practical tool for approximating how much credibility a declaration extracts. 


\section{An Anti-Skeptical Strategy}

This final section indicates how an anti-skeptical invariantist might embellish my proposal. I emphasize that this section is more speculative than the rest of the paper, and defending the embellishment goes beyond the paper's main goal.

In ordinary contexts uttering ' $Q$ ' is to assert that $Q$, but in highstakes contexts uttering ' $Q$ ' is to guarantee that $Q$. In ordinary contexts uttering ' $I$ think that Q' is to make a hedged or qualified assertion, but in high-stakes contexts uttering 'I think that Q' might be a way to assert that $Q$. This makes sense because ' $Q$ ' is no longer available for the job, but nevertheless we might still want or need to be able to continue simply asserting things, even when the stakes are high. The unadorned 'Q' was promoted a level, so it stands to reason that 'I think that Q' would likewise get promoted to take its place. ${ }^{25}$ For instance, in High Door uttering 'I think it's locked' the second time was to assert that it is locked. Moreover, everyone recognizes that, given my evidence, it was appropriate for me to repeat 'I think it's locked' in High Door. So assuming that knowledge is the norm of assertion, it follows that I continue to know that it is locked throughout High Door.

We could generalize this strategy to explain our linguistic beha-

${ }^{25}$ In response, one might argue that such a shift needn't be seamless, and thus could result in speech-act gaps. It does not seem necessary that 'I think that $Q$ ' would be promoted; maybe asserting that $Q$ is simply no longer an option when the conversation reaches that point. 
vior in the face of formidable skeptical hypotheses-extending the scope and power of our newly fashioned invariantism, stealing yet more thunder from the anti-skeptical contextualist-without conceding anything to the skeptic, aside from cleverness. We might not be willing to say 'I am not a handless brain in a vat' when confronted with the skeptical hypothesis that we are the unwitting victims of a malevolent neuroscientist, mere brains in vats being fed sensory stimuli that make it seem just as though we have hands. But even when challenged this way, we still are willing to say 'I think I am not a handless brain in a vat', which we all recognize as appropriate, and which, in the context, amounts to asserting that one is not a handless brain in a vat. Assuming that the knowledge account of assertion is true, then, it follows that we continue to know that we are not handless brains in vats, even in the skeptical context. ${ }^{26}$

${ }^{26}$ Thanks to Keith DeRose, James Dreier, Leo lacono, Ben Jarvis, Andrew Rotondo, Patrick Rysiew, Jonathan Schaffer, Ernest Sosa and Rob Stainton for very helpful conversation, feedback and advice. Thanks also to two anonymous referees. 


\section{References}

Austin, J. L. 1946.“Other Minds," Proceedings of the Aristotelian Society: Supplementary Volume 20, 148 - 87. Reprinted in J. L. Austin, Philosophical Papers, $3^{\text {rd }}$ ed., edited by J. O. Urmson and G. J. Warnock, 76 - 116, Oxford: Oxford University press.

. 1962. How to Do Things with Words. Oxford: Oxford University Press.

Blackson, Thomas. 2004. "An Invalid Argument for Contextualism." Philosophy and Phenomenological Research 68:344 345 .

Cappelen, Herman and Ernie Lepore. 2005. Insensitive Semantics: A Defense of Semantic Minimalism and Speech Act Pluralism. Malden, MA: Blackwell.

Cohen, Stewart. 1988. "How to be a Fallibilist." In Philosophical Perspectives 2:91- 123.

. 1999. "Contextualism, Skepticism and the Structure of Reasons." Philosophical Perspectives 13:57 - 89.

. 2005. "Contextualism Defended." In Contemporary Debates in Epistemology, edited by Matthias Steup and Ernest Sosa, 56 - 62, Malden, MA: Blackwell.

Conee, Earl. 2005. "Contextualism Contested." In Contemporary Debates in Epistemology, edited by Matthias Steup and Ernest Sosa, 47 - 56, Malden, MA: Blackwell.

DeRose, Keith. 1992. "Contextualism and Knowledge Attributions." Philosophy and Phenomenological Research 52:913 - 929.

. 1995. "Solving the Skeptical Problem." The Philosophical Review 104:1 - 52.

. 1999. "Contextualism: An Explanation and Defense." In The Blackwell Guide to Epistemology, edited by John Greco and Ernest Sosa, 187 - 205, Malden, MA: Blackwell

. 2002. "Assertion, Knowledge and Context." Philosophical 
Review, 111:167- 203.

. 2004. "The Problem with Subject-Sensitive Invariantism." Philosophy and Phenomenological Research 68:346 - 350.

Fantl, Jeremy and Matthew McGrath. 2002. "Evidence, Pragmatics, and Justification." The Philosophical Review, 111:67 - 94. and . 2007. "On Pragmatic Encroachment in Epistemology." Philosophy and Phenomenological Research, 75:558 - 589.

Fogelin, Robert and Walter Sinnott-Armstrong. 1997. Understanding Arguments: An Introduction to Informal Logic. New York: Harcourt Brace.

Hawthorne, John. 2004. Knowledge and Lotteries. Oxford: Oxford University Press.

Hazlett, Allan. Forthcoming. "The Myth of Factive Verbs." Philosophy and Phenomenological Research.

Schaffer, Jonathan. 2004. "From Contextualism to Contrastivism." Philosophical Studies 119:73 - 103. . 2006. "The Irrelevance of the Subject: Against Subject Sensitive Invariantism.” Philosophical Studies 127:87 - 107.

Sosa, Ernest. 1991. Knowledge in Perspective. Cambridge: Cambridge University Press. . 1999. "How to Defeat Opposition to Moore." Philosophical Perspectives, 13, Epistemology:141 - 153. . 2004. "Replies." In Ernest Sosa and His Critics, edited by John Greco, 273 - 325, Malden, MA: Blackwell.

. 2007. A Virtue Epistemology: Apt Belief and Reflective Knowledge, vol. 1. Oxford: Oxford University Press.

Stanley, Jason. 2005. Knowledge and Practical Interests. Oxford: Oxford University Press.

Unger, Peter. 1975. Ignorance: A Case for Skepticism. Oxford: Oxford University Press.

Williamson, Timothy. 2000. Knowledge and Its Limits. Oxford: 
Oxford University Press. 